\title{
Radiographic features and behaviors of neuroendocrine tumors: can we judge a book by its cover?
}

\author{
Tyler J. Mouw, Charles R. Scoggins \\ Hiram C. Polk, Jr, MD Department of Surgery, Division of Surgical Oncology, University of Louisville, Louisville, KY, USA \\ Correspondence to: Charles R. Scoggins, MD, MBA. 315 E Broadway, Louisville, KY 40202, USA. Email: charles.scoggins@louisville.edu. \\ Comment on: Armstrong EA, Beal EW, Shah M, et al. Radiographic characteristics of neuroendocrine liver metastases do not predict clinical outcomes \\ following liver resection. Hepatobiliary Surg Nutr 2020;9:1-12.
}

Submitted May 01, 2021. Accepted for publication Jun 03, 2021.

doi: $10.21037 / \mathrm{hbsn}-21-174$

View this article at: https://dx.doi.org/10.21037/hbsn-21-174

Gastrointestinal and pancreatic neuroendocrine tumors are uncommon diseases which can have a varied clinical course. This category of tumor includes functional and nonfunctional variants and despite the common developmental pathway for the cells of origin, the tumor subtypes can demonstrate strikingly different behaviors. Due to the rarity and heterogeneous courses of this family of tumors, investigators have attempted to utilize pre-operative data to determine the prognosis prior to initiating treatment. The recent publication by Armstrong et al. attempts to expand on prior works which demonstrate poor outcome based on radiographic features of the primary tumor such as arterial phase hypoenhancement and/or calcifications (1-4). In these studies, such findings were markers for early or synchronous hepatic metastasis.

At its core, the fundamental question being asked is "can you judge a book by its cover?". Can we accurately predict biologic behavior and patient survival based on (somewhat) static non-functional cross-sectional CT imaging? It is desirable to think that one could determine an individual patient's survival before undertaking a major tumor resection, such as a hepatectomy. This would be especially attractive if we could make such a prognostication based on readily-available, commonplace imaging techniques. Unfortunately, CT imaging, even when done well with precise timing of the contrast bolus, falls short. In their study, Armstrong et al. included 82 patients with known liver metastases from a variety of gastrointestinal and pancreatic primary locations. They did not find an association between typical markers of aggressive tumor biology (multifocal synchronous lesions, high Ki-67 index, primary tumor location, etc.) with the presence of calcifications in the metastases. Furthermore, they did not demonstrate an overall or recurrence-free survival difference for patients with or without calcifications. Likewise, they reported similar findings with arterial enhancement status. These findings seem to contradict the previous publications which evaluated primary tumors (2-4). This again begs the question: can tumor biology be accurately predicted based on non-functional cross-sectional imaging? The findings presented above cast doubt on this, especially if we are going to rely on calcifications or contrast enhancement patterns. Elsewhere in pathophysiology we associate intralesional calcifications with chronicity, particularly in situations of inflammation or local tumor response. If the presence of calcium in a neuroendocrine tumor is to reflect an aggressive nature, are we to infer that some tumors are older and, over time, have accumulated a greater malignant nature? In such a scenario, once the cat is out of the bag and metastases develop, the clinical outcomes between calcified and non-calcified or hyper- vs. hypo-enhancing lesions appear to converge. This would suggest that these findings may be less associated with tumor biology and more with tumor chronicity. We see similar patterns among other unrelated tumors such as intraductal papillary mucinous neoplasm (IPMN), where calcifications are associated with tumor size which, again, is a function of the interplay between tumor age and aggression (5). Younger, more aggressive tumors and older more indolent tumors can both grow to similar sizes. The development of metastatic potential is not a pre-destined event along this process, especially for neuroendocrine carcinoma. In not finding an 
association between radiographic features of the metastases and outcomes, the authors have demonstrated something important: unfavorable tumor biology is not limited to rapidly growing tumors. "Bad biology" may also include insidious tumors which elude detection for some time and can grow to large size and/or invade critical structures. At the end of the day, it is genotype that largely determines the phenotype.

This expanded definition of "bad biology" does not necessarily diminish the utility of prior reports on the radiographic features of neuroendocrine carcinoma. Knowing that calcifications or hypo-enhancement are might be associated with the presence of metastases may still have clinical utility even if that utility is diminished when evaluating those features in the setting of known metastases. For the surgeon evaluating a patient for resection, the risk of micro-metastatic subclinical disease is always a top concern. Which scenario is more concerning to the oncologic surgeon: a rapidly growing primary tumor which may not yet have developed metastatic potential or, if it has, the metastases may exhibit equally rapid growth $v s$. a slow-growing, indolent tumor which has had ample time to shed occult metastases? These scenarios are highly speculative, and it is clear that further work is needed for us to provide better prognostic information. We applaud the authors for evaluating this question in the setting of metastatic disease as these findings further define the context in which radiographic features may be helpful. These data are thought provoking and lead one to consider whether functional radiographic studies such as dotatate PET might shed light and correlate with tumor histology or genotype.

\section{Acknowledgments}

Funding: None.

\section{Footnote}

Provenance and Peer Review: This article was commissioned by the editorial office of Hepatobiliary Surgery and Nutrition. The article did not undergo external peer review.

Cite this article as: Mouw TJ, Scoggins CR. Radiographic Features and behaviors of neuroendocrine tumors: can we judge a book by its cover? HepatoBiliary Surg Nutr 2021;10(4):573-574. doi: $10.21037 / \mathrm{hbsn}-21-174$
Conflicts of Interest: Both authors have completed the ICMJE uniform disclosure form (available at https://hbsn. amegroups.com/article/view/10.21037/hbsn-21-174/coif). The authors have no conflicts of interest to declare.

Ethical Statement: The authors are accountable for all aspects of the work in ensuring that questions related to the accuracy or integrity of any part of the work are appropriately investigated and resolved.

Open Access Statement: This is an Open Access article distributed in accordance with the Creative Commons Attribution-NonCommercial-NoDerivs 4.0 International License (CC BY-NC-ND 4.0), which permits the noncommercial replication and distribution of the article with the strict proviso that no changes or edits are made and the original work is properly cited (including links to both the formal publication through the relevant DOI and the license). See: https://creativecommons.org/licenses/by-nc-nd/4.0/.

\section{References}

1. Armstrong EA, Beal EW, Shah M, et al. Radiographic characteristics of neuroendocrine liver metastases do not predict clinical outcomes following liver resection. Hepatobiliary Surg Nutr 2020;9:1-12.

2. Poultsides GA, Huang LC, Chen Y, et al. Pancreatic neuroendocrine tumors: radiographic calcifications correlate with grade and metastasis. Ann Surg Oncol 2012;19:2295-303.

3. Marrache F, Vullierme MP, Roy C, et al. Arterial phase enhancement and body mass index are predictors of response to chemoembolisation for liver metastases of endocrine tumours. Br J Cancer 2007;96:49-55.

4. Worhunsky DJ, Krampitz GW, Poullos PD, et al. Pancreatic neuroendocrine tumours: hypoenhancement on arterial phase computed tomography predicts biological aggressiveness. HPB (Oxford) 2014;16:304-11.

5. Perez-Johnston R, Narin O, Mino-Kenudson M, et al. Frequency and significance of calcification in IPMN. Pancreatology 2013;13:43-7. 